\title{
Use of Medical Information and Digital Services for Self- Empowerment before, during, and after a Major Disaster
}

\author{
Susumu Fujii, ${ }^{1}$ Sayuri Nonaka ${ }^{1}$ and Masaharu Nakayama ${ }^{1,2}$ \\ ${ }^{1}$ Disaster Medical Informatics Lab, International Research Institute of Disaster Science (IRIDeS), Tohoku \\ University, Sendai, Miyagi, Japan \\ ${ }^{2}$ Department of Medical Informatics, Tohoku University School of Medicine, Sendai, Miyagi, Japan
}

\begin{abstract}
Disaster response procedures have been developed and improved following the Great East Japan Earthquake. Innovative services have also been created through digital transformation, including an acceleration and deepening of artificial intelligence technology. Things that were once technically impossible are now possible. These innovative technologies will spread across various fields, and disaster response will not be an exception. The Ministry of Health, Labour and Welfare is promoting the use of personal health records in a way that effectively supports the management of treatments by using data from wearable devices and specific applications. During the COVID-19 pandemic, the trade-off between protecting personal information and enabling social benefits, such as in the use of digital tracking, and infodemics, including misinformation, have become new social challenges. Reviewing past disaster preparedness and the services and value provided by digital transformation indicates what new disaster preparedness should be. Digital transformation does not require literacy (ability to collect, analyze, and use information) but competence (beneficial behavioral traits derived from experience). Understanding behavior through data and enabling rational behavior are crucial. By increasing human productivity, we can save time and improve self- and mutual-help in times of disaster. Medical information and digital services must be properly used in normal times. A society that uses such services will be more disaster resilient.
\end{abstract}

Keywords: digital transformation; disaster medicine; Great East Japan Earthquake; medical informatics; personal health record

Tohoku J. Exp. Med., 2021 November, 255 (3), 183-194.

\section{Introduction}

The Great East Japan Earthquake of March 2011 was a disaster of an unprecedented scale (Ishigaki et al. 2013; Orui et al. 2015; Reconstruction Agency 2020). Over the past 10 years, stakeholders in various fields have been studying and developing methods of disaster prevention, mitigation, and response (Egawa 2021).

In Japan, the importance of business continuity plans (BCPs) have been recognized from the Great East Japan Earthquake (Cabinet Office 2013). According to a survey conducted by the Cabinet Office in 2019 (Cabinet Office 2020 ), $68.4 \%$ of companies with capital of more than 1 billion yen and more than 50 regular employees, and $34.4 \%$ of companies with less than 1 billion yens capital but more than 50 regular employees have formulated BCPs, and the proportion is increasing every year. Furthermore, a majority of the companies with BCPs review them on a regular basis.

A 2021 survey by the Ministry of Internal Affairs and Communications (MIC) presented the status of $\mathrm{BCP}$ response by the administrative units (MIC 2021). There is a $100 \%$ rate of BCP formulation for administrative units in prefectures and a $94.4 \%$ rate for municipal units, which indicates that a substantial number of BCPs have been formulated. However, $91.5 \%$ of prefectural administrative units have formulated BCPs for efficiently receiving support in the event of a disaster in the form of people and relief supplies from other prefectures, whereas only $45.0 \%$ of municipal administrative units have done so (MIC 2021).

Received July 20, 2021; revised and accepted August 24, 2021. Published online December 2, 2021; doi: 10.1620/tjem.255.183.

Correspondence: Susumu Fujii, Department of Disaster Medical Informatics, Tohoku University School of Medicine, 2-1 Seiryo-machi, Aoba-ku, Sendai, Miyagi 980-8575, Japan.

e-mail: sfujii@sfujii.net

(C)2021 Tohoku University Medical Press. This is an open-access article distributed under the terms of the Creative Commons Attribution-NonCommercial-NoDerivatives 4.0 International License (CC-BY-NC-ND 4.0). Anyone may download, reuse, copy, reprint, or distribute the article without modifications or adaptations for non-profit purposes if they cite the original authors and source properly.

https://creativecommons.org/licenses/by-nc-nd/4.0/ 
Only $33.2 \%$ of municipalities have formulated all six stipulated items (Table 1) in their BCPs (Table 2), and this omission, including any others, must be remedied.

The development of BCPs as a part of disaster prevention, mitigation, and response has thus been progressing in terms of scale in companies and administrations. The following step is business continuity management (BCM), which requires not only the introduction of BCPs but also their operations and review on an ongoing and integrated basis.

The Ministry of Health, Labour and Welfare (MHLW) conducted a nationwide survey of medical institutions nationwide in 2018 (MHLW 2019c) and found that BCP formulation has been achieved in all base hospitals for disasters because it is also a facility requirement; however, the rate of $\mathrm{BCP}$ formulation in other medical facilities was only 25\% (MHLW 2019c). The MHLW has been promoting the formulation of BCPs (Sasaki et al. 2020) through its Guide for Preparing Hospital Disaster Response Plans Based on the Concept of BCPs and BCP Formulation Training Program.

The development of medical support during the disaster is also crucial. To this end, the MHLW has been promoting the development of a macroscopic system. The Disaster Medical Assistance Team (DMAT [MHLW] 2005; Kondo et al. 2012, 2019), launched in April 2005 after the
Great Hanshin-Awaji Earthquake, has undergone improvements through repeated practice and can now provide a wide range of medical services, including hospital support, maintaining, expanding hospital functions in the disaster area, and emergency medical services in ordinary times. This function has become an indispensable part of today's disaster response. An internet search reveals more than 20 organizations that provide similar support to disasterstricken areas, including administrations, medical associations, academic societies, and group hospitals. However, the activities of these organizations encounter complex problems for the recipients of support, and developing plans to receive aid and establishing the nature of the support in advance is essential.

The COVID-19 pandemic, which is another type of disaster, has also been spreading globally from December 2019. In responding to disasters related to infectious diseases, individual and decentralized evacuation responses are required, such as lockdown policies in other countries, in contrast to setting up evacuation centers and having people evacuate en masse, which is required in natural disasters, such as earthquakes and typhoons (Alfano and Ercolano 2020).

In addition, there is a need for information technology (IT)-based responses that can identify infection routes and help manage infected persons, which has been observed in

Table 1. The six key elements to be specified in the business continuity plan (BCP).

1 A clear order of succession in the absence of the head of the government and a system for gathering staff

2 Identification of alternative government buildings in the event that the main government building cannot be used

3 Securing electricity, water, food, etc.

4 Securing various means of communication that can be easily connected even in times of disaster

5 Back up important administrative data

6 Organize priority tasks in the event of an emergency

Source: Ministry of Internal Affairs and Communications press release "Results of a survey on the status of business continuity planning in local governments", February 25, 2021.

Table 2. Status of formulation of the six key elements to be specified in the business continuity plan (BCP).

\begin{tabular}{lrrrr}
\hline & \multicolumn{2}{c}{ Prefectural Government } & \multicolumn{2}{c}{ Municipalities } \\
\cline { 2 - 5 } & \multicolumn{2}{c}{ June 1, 2020 } & \multicolumn{2}{c}{ June 1, 2020 } \\
\hline 6 elements & 40 & $85.10 \%$ & 546 & $33.20 \%$ \\
5 elements & 5 & $10.60 \%$ & 471 & $28.60 \%$ \\
4 elements & 0 & $0.00 \%$ & 303 & $18.40 \%$ \\
3 elements or less & 2 & $4.30 \%$ & 324 & $19.70 \%$ \\
\hline
\end{tabular}

Source: Ministry of Internal Affairs and Communications press release "Results of a survey on the status of business continuity planning in local governments", February 25, 2021. 
other countries that have conducted successful quarantines (Nakamoto et al. 2020; Steinbrook 2020). In Japan, however, social consent for the handling of personal information remains an issue. Numerous problems have been caused by hastily constructed systems (MHLW [COCOA] 2021).

Policies and goals bearing on disaster prevention, mitigation, and disaster response include the Sustainable Development Goals (SDGs) (UN 2015), which are included in the 2030 Agenda for Sustainable Development and have been adopted unanimously by member states at the United Nations Summit of September 2015. The SDGs are international goals that aim to create a sustainable and better world by 2030 and comprise of 17 goals and 169 targets. The eleventh goal to "Make cities and human settlements inclusive, safe, resilient and sustainable" relates to disasters (UN 2016a).

Target 11 b states "By 2020, substantially increase the number of cities and human settlements adopting and implementing integrated policies and plans towards inclusion, resource efficiency, mitigation and adaptation to climate change, resilience to disasters, and develop and implement, in line with the Sendai Framework for Disaster Risk Reduction 2015-2030, holistic disaster risk management at all levels" (UN 2016b).

Technological innovation, 10 years after the Great East Japan Earthquake, is rapidly developing. For example, in IT and information and communication technology (ICT), large global platforms, such as Google, Apple, Facebook, and Amazon, have been established, and social networking services (SNS) have spread along with sensing technologies, such as Internet of Things (IoT) and wearable devices; high-speed communication technologies, such as $5 \mathrm{G}$, and artificial intelligence (AI) technologies, such as machine learning and deep learning. The development of AI (Sung et al. 2020) technologies, such as machine learning and deep learning, is remarkable. These technologies have been grouped together under the name of the Fourth Industrial Revolution (Schwab 2015), and digital transformation (DX) (Stolterman and Fors 2004) using innovative technologies is being demanded at an accelerating pace as a means of addressing future social issues.

Thus, it is time to review the BCPs and the response methods for disaster prevention, disaster mitigation, and disaster recovery that have been developed over the 10 years from the Great East Japan Earthquake and their preconditions. What was previously considered impossible will become possible with the advancement of technology. Disaster prevention, mitigation, and response are no exception to this natural progression of developing new means of solving problems.

In the medical field, substantial research is being conducted on clinical support by using AI. Furthermore, medical information is being used in a more personal way. The MHLW is also promoting the use of personal health records (PHRs) in the Data-Health Reform (Sasako 2020).
In this review, we consider how disaster prevention, mitigation, and disaster response must be conducted over the coming decade considering social and technological conditions, current states of affairs, and global goals, such as the SDGs. The current state of disaster preparedness in Japan will be reviewed, particularly with regard to medical care and contemporary values, such as those expressed in the SDGs, and the most effective communication and digital technologies, such as those defined as DX, will be investigated and reviewed to examine how disaster mitigation, disaster prevention, and disaster response must be conducted over the following decade. In particular, this study proposes a new type of a medical response to disasters in the careful consideration of changes engendered by the use of DX and PHR. Presenting these responses as models to be realized over the following decade is crucial for developing a resilient society that can respond adequately to disasters.

\section{Disaster Prevention, Mitigation, and Response in the 10 Years since the Great East Japan Earthquake and the 10 Years to Come}

\section{$D X$ for disaster prevention, mitigation, and disaster response}

In 2018, the Ministry of Economy, Trade and Industry (METI) established its Study Group for Digital Transformation to help Japanese companies to promote DX, and published its DX Report; Overcoming the IT System Cliff of 2025 and Full-Scale Development of DX (METI 2018a). In the report, the need for guidelines was indicated, after which the Guidelines for Promoting Digital Transformation (METI 2018b) were formulated. In the report, DX is defined as "the ability of companies to leverage the third platform (cloud, mobility, big data/analytics, and social technologies) to create new products, services, and business models that improve the customer experience both online and in the real world, while responding to disruptive changes in the external ecosystem (customers, markets, employees) and driving changes in the internal ecosystem (organization, culture, employees)." In addition, it is defined as "creating value and establishing competitive advantage by transforming the customer experience, both online and in the real world, through new products, services, and business models" (METI 2018a).

To understand DX, we must consider the difference between digitization and digitalization. Both terms refer to making something digital; however, in digitization, digital technology is used to perform tasks that were once performed in the analog form to improve business efficiency, increase productivity, and reduce costs. Digitalization is the use of digital technology to provide services in a new business model that has never existed before, thereby creating new profit and value.

For example, in digitization, medical records, which were once recorded on paper, are converted into data (MHLW 2001), and medical care in the form of medical 
interviews and consultations is conducted online (MHLW 2018). Although the number of applications for online medical care has increased because of the COVID19 pandemic and online medical care is becoming more widespread, no major changes have been seen in business processes, and the scope of business efficiency and cost reductions is limited to the incorporation of digital technology into the existing operations.

Digitalization creates opportunities to earn additional profit and value by streamlining the business process itself. For example, in a treatment model (Mora et al. 2019; Roche Diabetes Care 2021), interventions are provided by treatment applications installed on smartphones during the selfmanagement period between hospital visits. In some models, 24-h continuous data is drawn from wearable devices and other real-world data (Concato 2020) to predict disease onset and support diagnosis by using big data analysis. New value will be created when these unconventional treatment models are provided and treatment is implemented based on patient engagement (WHO 2016).

Digitalization can create new value, and it is a key technology for securing competitive advantages and achieving DX. In developing disaster prevention, mitigation, and relief, simply adopting digitization is not sufficient; one must also consider the diversity of new technologies and data, and adopt digitalization to develop new values. If advantages can be obtained over conventional methods of disaster prevention, mitigation, and response, it will enable DX to find greater purchase in the field of disaster medicine.

Personal health record (PHR)-based disaster prevention, mitigation, and disaster response

Data-health reform and data variety: In Japan, major medical policies during 2000-2010 included the Health Promotion Law (Government of Japan 2002; MHLW 2019b) and the start of specific health checkups and health guidance to increase awareness regarding the risk of lifestyle-related diseases. During 2011-2015, the Data-Health Plan was developed (MHLW 2017c) to set numerical targets for the rate of health checkups, to optimize medical costs, and to help prevent serious diseases. In 2016, the Act on Anonymized Medical Data That Are Meant to Contribute to Research and Development in the Medical Field was passed (Government of Japan 2017) to allow big data to be accumulated and to utilize the results of its analysis for policymaking. The Data-Health Reform will be in force in 2020 (MHLW 2017a) to promote the utilization of healthcare information. It will also promote the digitalization of healthcare.

In addition, to address the physician shortage (Nomura et al. 2009; Takata et al. 2011) and the 2025 problem (Takahashi 2014), community-based medicine (MHLW 2016) has been promoted instead of single facility-based medicine, and medical ICT (MHLW 2014) has been developed to share medical information.
However, the MHLW has indicated that health information "has not always been in a form that draws on the power of the frontline, industry, government and academia, or that allows patients and citizens to realize the benefits." Therefore, in 2017, a new headquarters for the Data-Health Reform (MHLW 2017b) was established within the MHLW.

This reform effort has four goals; promotion of (1) genomic medicine and AI utilization, (2) PHRs that link personal data to improvements in daily life, (3) information utilization in medical and nursing care settings, and (4) effective database utilization. Furthermore, in July 2020, the Data-Health Intensive Reform Plan (MHLW 2020) was announced, with three action plans; (1) expansion of the system that allows patients and medical institutions nationwide to check medical information, (2) establishment of an electronic prescription system, and (3) expansion of the system that allows patients to utilize medical information.

The use of individuals' medical information is regulated through PHR (Xiao et al. 2021) services utilizing the Myna Portal (Cabinet Office 2017). In particular, Action (1) indicates the following: "(1) Even if your medical institution is affected by disaster, another medical institution can check the patient's information, making it easier to continue necessary treatment. (2) More appropriate and prompt examination, diagnosis, and treatment of patients with impaired consciousness who are transported to emergency rooms by confirming their drug information. (3) By consolidating information on patients across multiple medical institutions, the system will contribute to the medical care of family doctors, who are required to have a comprehensive understanding of patients. (4) To reduce the burden of medical personnel in making inquiries and confirmations. (5) To supplement patient information in cases where faceto-face consultations are difficult, such as during the spread of infectious diseases. (6) Reduction of duplication of medication, etc." These are only some of the many anticipated, positive effects of reform.

There is currently no mechanism for sharing medical information and identifying individuals, and it is difficult to develop social consent for the handling of medical information by nonprimary medical institutions. However, under this regime, it may become possible to manage PHRs when the infrastructure is established and consent is obtained. This approach may be used in disaster prevention, mitigation, and response, and the preconditions for the target data of response methods will change substantially.

PHRs and regional medical cooperation: An MHLW Report (2011a) indicated that medical institutions in the three Tohoku prefectures (i.e., Iwate, Miyagi, and Fukushima) suffered damages in the Great East Japan Earthquake (Table 3). In summary, 10 hospitals and 83 clinics buildings collapsed. Furthermore, more than 2,000 medical institutions were forced to restrict outpatient services immediately after the earthquake. Finally, 10 medical institutions lost medical records because of the tsunami and 
Table 3. Status of damage to hospitals and clinics in the affected areas (As of July 11, 2011).

\begin{tabular}{|c|c|c|c|c|c|c|c|c|c|}
\hline \multirow{4}{*}{ Prefectures } & \multicolumn{3}{|c|}{ Hospitals } & \multicolumn{6}{|c|}{ Clinics } \\
\hline & \multirow{3}{*}{$\begin{array}{l}\text { Number } \\
\text { of } \\
\text { hospitals }\end{array}$} & \multirow{2}{*}{\multicolumn{2}{|c|}{$\begin{array}{c}\text { Damage caused by the } \\
\text { Great East Japan } \\
\text { Earthquake }\end{array}$}} & \multirow{2}{*}{\multicolumn{2}{|c|}{ Number of clinics }} & \multicolumn{4}{|c|}{ Damage caused by the Great East Japan Earthquake } \\
\hline & & & & & & \multicolumn{2}{|c|}{ Total destruction } & \multicolumn{2}{|c|}{ Partially collapsed } \\
\hline & & $\begin{array}{c}\text { Total } \\
\text { destruction }\end{array}$ & $\begin{array}{l}\text { Partially } \\
\text { collapsed }\end{array}$ & $\begin{array}{c}\text { Medical } \\
\text { departments }\end{array}$ & Dentistry & $\begin{array}{c}\text { Medical } \\
\text { departments }\end{array}$ & Dentistry & $\begin{array}{c}\text { Medical } \\
\text { departments }\end{array}$ & Dentistry \\
\hline Iwate & 94 & 3 & 59 & 927 & 613 & 38 & 46 & 76 & 79 \\
\hline Miyagi & 147 & 5 & 123 & 1,626 & 1,065 & 43 & 32 & 581 & 367 \\
\hline Fukushima & 139 & 2 & 108 & 1,483 & 919 & 2 & 5 & 516 & 374 \\
\hline Total & 380 & 10 & 290 & 4,036 & 2,597 & 83 & 83 & 1,173 & 820 \\
\hline
\end{tabular}

Source: "Damage to Base Hospitals for Disaster Medical Services in the Great East Japan Earthquake", Ministry of Health, Labour and Welfare, November 11, 2011.

other damage, thereby making it difficult to provide medical services immediately after the disaster. A survey by the MIC found that $27 \%$ of the hospitals had data loss (MIC 2012). Preventing the loss of medical records is a crucial issue for ensuring the continuous provision of medical care.

Therefore, the Great East Japan Earthquake Reconstruction Initiative Council announced in its Proposal for Reconstruction: Hope in the Midst of Tragedy (CAS 2011) that "the sharing of medical records and other medical information must be promoted for crisis management in the future" and that "in light of the loss of data in the fields that support local communities, such as government, medical care, and education, due to the earthquake, it is necessary to share medical records and other medical information. Furthermore, in light of the fact that data in the fields that support local communities, such as government, medical care, and education, were lost due to the earthquake, further digitization of information should be promoted in these fields, and the introduction of cloud services should be strongly promoted." A survey reported by Tanaka (2012) also suggests that this response be performed through "cloud computing (digitization of medical information and connection to regional medical information networks)" and "backup functions (remote backup functions and regional medical coordination functions)"; furthermore, "need for a disaster-resistant medical information system" is indicated.

The Ministry of Education, Culture, Sports, Science and Technology (MEXT) launched The Gemini Project (Kimura 2014) in 2012 to store backup data from the hospital information systems of 42 national universities and 46 university hospitals across the country in data centers located in eastern and western Japan. Unless the cloud centers, which are more than 1,000 kilometers away from each other, are damaged at the same time, the possibility of medical information being lost is extremely low. Even if the server equipment at the medical facility is damaged, the system can be recovered from the data stored in the cloud if the server is later repaired. However, this type of mitigation initiative still entails a significant cost burden.

The development and utilization of regional coopera- tion systems for information sharing is being promoted. In Miyagi Prefecture, the Miyagi Medical and Welfare Information Network (Ido et al. 2019; Nakayama et al. 2021) was established to share information among hospitals, clinics, pharmacies, and nursing care facilities in the prefecture. As of the end of March 2021, the number of registered consenting patients exceeded 100,000, and the total number of backup medical records exceeded 14 million patients. Furthermore, clinics in Fukushima Prefecture, which borders on Miyagi Prefecture's southern medical area, have joined the system, thereby steadily expanding the scope of the system beyond the administrative medical area units in a way that is consistent with the actual conditions of the living areas.

However, the preservation of these remote areas and the regional medical network refer to preparations and information sharing on the medical provider side, particularly medical facilities. However, according to the Reconstruction Agency, 4,371 evacuees across three prefectures of Tohoku cannot return to their pre-disaster residential areas (as of the end of May 2021) (Reconstruction Agency 2021). Their medical information has virtually been lost. In other words, once they leave their original place of residence following the disaster, despite their family doctor's information system being restored and medical information being shared, they will not have their own medical information in their new place of residence; it will be difficult for them to receive full benefits. To manage such issues, a method based on a new sense of values, such as sharing information at the national level, preserving medical records independent of evacuation and relocation locations, and using PHRs to manage their own medical information, as described in the Data-Health Reform, will be required for future disaster prevention, mitigation, and response.

Prescription drugs and drug logistics: Electronic medication notebooks, electronic prescriptions, and drone technology: After the Great East Japan Earthquake, excluding the exception of the lost medical records immediately after 
the disaster and during the acute phase, numerous drugrelated reports (Hirokawa et al. 2014) and papers (Tanno 2014) have reported problems with prescription. The major issues are flow in prescription handling and logistics (Ujiie 2013). In the immediate aftermath of a disaster or during the acute phase, medical supplies are assumed to be accommodated by inventories at medical institutions and through the support medicines brought in by DMATs and others. However, prescribing for patients with chronic diseases after the acute phase is also a concern.

A chart of the prescription process (JPA 2012a) is included in the report of the Pharmaceutical Association of Japan on the Great East Japan Earthquake. Patients' memories of the medications they were taking were vague, and it is dangerous to prescribe based on possibly inaccurate information. At the time of the earthquake, they sought to secure prescriptions by using various procedures; however, these processes were complex and uncertain. Thus, the medication notebook, where was used for regular records, was useful (JPA 2012b).

In the case of typhoons, evacuation can be conducted according to pre-disaster timelines, and thus, in such cases, it may be possible to sufficiently validate the presence of regular medications and medical notebooks among the items. However, during an earthquake, such a prediction is difficult, and in situations where residents are evacuating with nothing but their clothes, they may leave their regular medication or medication records behind. These records undeniably may be lost in such situations. Methods of educating people regarding the effectiveness of medication notebooks and promoting the regular use of the notebook must be considered conditional if it is expected that the notebook will be effective even during a disaster and that if it is lost, all necessary information will be lost.

At present, electronic prescriptions are being promoted as a part of the health data reform. For this digitization, the Japan Pharmaceutical Manufacturers Association has created a system for centralized information browsing (Watanabe 2017) and has begun developing a foundation for utilization in 2016 called E-Yaku LINK (JPA 2016a). From then, various electronic drug diaries based on this standard have been released as applications (JPA 2021). These diaries include PHRs and are expected to provide daily convenience by providing functions, such as selfmedication management, contra-indications, and inventory management, that were not possible with earlier systems. They could also be used for future disaster prevention, mitigation, and response (JPA 2016b).

There is a current initiative of employing drones to use the airways for logistics in case ground transportation infrastructure becomes nonfunctional (MLIT 2021a; MoshrefJavadi and Winkenbach 2021). Originally, this demonstration project was developed to deliver supplies to remote islands; however, it has reached a stage where it is technically feasible for broader applications (MLIT 2021b).

If new technologies arrive, the new drone-based deliv- ery of supplies may be associated with PHRs (Orii 2018; Khan et al. 2021). A PHR can be used to determine the type and quantity of drugs required and to determine the location of delivery. In the event of a disaster, electronic prescriptions can be issued through online medical services and delivered directly to individuals. If such systems are constructed, the onsite load on hospitals and pharmacies during a disaster will be reduced, thereby allowing them to focus their human resources on injured evacuees or on those in serious conditions with physical constraints, which will have a synergistic effect.

This method of prescription could be used in normal times for elderly people who have difficulty moving. Furthermore, if it is used by patients with chronic diseases, it can help prevent serious illnesses during and immediately after disasters (Dugas et al. 2020). The construction of such services will be necessary for future methods of disaster prevention, mitigation, and response.

\section{Distributed evacuation and support and self-help}

How shelters can involve DX: The Tokyo Metropolitan Government's Grand Design for Earthquake Disaster Reconstruction (Tokyo Metropolitan Government 2001) indicates the importance of examining in advance what the goal of urban reconstruction should be (Nakamura 2011). Furthermore, implementing such measures in advance rather than only when the disaster appears is crucial.

Tokushima Prefecture is promoting a Tokushima Model (Iwaka 2016) for pre-disaster reconstruction, thereby adopting the premise of the Nankai Trough Earthquake. This model considers social risks, such as the declining population; low birthrate, aging society and depopulation; and natural disaster risks, including the Nankai Trough, without separating them and promotes urban development when sharing a future vision of reconstruction. In particular, assuming tsunami damage, they forecast areas to be on alert for damage and consider land use models and urban planning based on the results. Public facilities in the warning areas must be relocated to higher ground before the disaster strikes, and residents must be educated on the need to take measures in advance.

If evacuation is unavoidable because of a tsunami, flood, or landslide, people will inevitable have to evacuate to evacuation centers. Evidently, there is no need to go to an evacuation center if your life and residence are safe. You can calmly evacuate your home or follow directives to make your house earthquake-proof and secure food. Not being required to go to an evacuation shelter is reasonable in a disaster response based on self-help, and it is also useful for reducing the burden on evacuation centers. The Tokyo Disaster Prevention (Tokyo Metropolitan Government 2015) published by the Tokyo Metropolitan Government also recommends such evacuation.

As earthquake-resistant design and construction technologies advance, the percentage of evacuees, who can evacuate in home, is expected to increase. With this possi- 
bility increasing, evacuation centers will need to become service centers where services that cannot be received at home are provided. Furthermore, information obtained from being in an evacuation center (e.g., safety information and administrative procedures) may not be conveyed to evacuees at home, thereby creating an information gap that could lead to a decline in the overall quality of governance.

Regarding future disaster prevention, mitigation, and response, creating a platform that can be operated as a virtual evacuation center by connecting evacuees at home and evacuation centers as function centers through ICT. Evacuation centers must provide safe and efficient medical services involving shared information on medical history, prescriptions, allergies, etc., by associating regional cooperation systems and PHRs. For evacuees at home, using DX at evacuation centers by combining medical services such as online consultation, delivery of supplies by drone, and medication management by application will be necessary.

Artificial intelligence and triage: The MHLW's Disaster Prevention and Mitigation Operations Plan (MHLW 2011b, 2019a) calls for a manual to be prepared for accepting patients in the event of a disaster, and in the case of the Tokyo Metropolitan Government's Bureau of Health and Welfare (Tokyo Metropolitan Government 2012), the primary activities to be conducted immediately after a disaster are shown, and it is indicated that triage will take place at medical aid stations and other facilities.

A triage report has been published on the Great East Japan Earthquake (Fujimori 2019), wherein cases categorized as red or yellow should be accepted at the disaster base hospital or a hospital associated with the disaster base hospital. Alternatively, in case that sufficient medical and personal resource is not possible in the regional disaster base hospital, the patients can be transported to a wider area. Green tags indicate minor cases that do not require inpatient care and can be treated at emergency medical aid stations or medical aid stations set up at evacuation centers (Tokyo Metropolitan Government 2019).

Minor cases can be treated at first aid stations, whereas the number of evacuees, particularly those evacuating in home, may have to cope with the situation on their own. They can use the internet and SNS to identify symptoms and information on how to cope. However, obtaining adequate knowledge and coping methods is not always possible. From the Great East Japan Earthquake, SNS has become an increasingly crucial tool for communicating information during disaster; however, there are reports that it cannot always be used effectively because of information hoaxes and explosions (Fujishiro et al. 2018). This selfresponse method has many challenges, particularly because with the increasing number of evacuations in home, the number of self-determined cases that do not undergo triage will also increase.

In the Ishinomaki Red Cross Hospital triage lawsuit that occurred after the Great East Japan Earthquake (Inoue
2019), a bereaved family sued the hospital after the elderly patient who had been categorized with the green tag, fell ill and died. Triage is a major social concern in the chaos of the disaster with the care of the elderly in a situation overflowing with rescuers; in particular, the responsibility that should be placed on medical personnel who are victims of the disaster but are also rescuers must be examined. Naturally, this is a life-and-death concern, and thus, medical facilities have implemented disaster drills, improved record keeping for disasters, and manuals for managing those who cannot return home. However, the self-help of patients remains a concern.

The use of digital healthcare applications that utilize PHR, AI, and other technologies may help patients help themselves and protect their lives. If these are sufficiently effective during normal times, people can avoid taking actions based on uncertain information from SNS and other sources. Such a PHR and AI technology is a promising method for disaster prevention, mitigation, and disaster control.

Managing chronic diseases: A study of the Great East Japan Earthquake included a case study of diabetic patients: during the disaster, it was not uncommon for type-1 diabetics to have extra insulin (Fujiwara et al. 2013), which they could use during the evacuation. Moreover, evacuation food is primarily carbohydrates, thereby making it difficult for these patients to control their blood glucose levels. Research shows that blood glucose levels following the disaster were generally higher than before, thereby returning to pre-disaster levels after six months (Kamimura et al. 2014).

A study by DMAT reported that in the first $72 \mathrm{~h}$ after the Great East Japan Earthquake, the number of seriously injured trauma victims was lower than that anticipated, and other medical must be increased in the acute and subacute phases. The number of deaths increased in isolated hospitals and places where supplies were scarce (Koido et al. 2011). Supply questions meant life or death. This finding underlines the importance of matching supply and demand through drones and other means as mentioned previously. The results of the blood glucose survey indicate that expert support is required, all the more so under abnormal evacuation conditions; however, this will be difficult to achieve.

A United Kingdom study (Porumb et al. 2020) used AI to detect hypoglycemic events from electrocardiography data as measured by wearable devices. In the United States, WellDoc's BlueStar (Welldoc 2021) provides a prescription app for type-2 diabetics. This prescription app was shown to be useful in a large-scale clinical trial in 2010 and was approved by the Food and Drug Administration. In Japan, Astellas Pharma Inc. concluded a commercialization agreement in November 2019 (Astellas Pharma and Welldoc 2019), which will soon be approved. This type of digital health-based disease management is expected to expand its scope of diseases and become established as a treatment 
method. In the BlueStar clinical trial, the hemoglobin A1c $(\mathrm{HbAlc})$ levels in the control group by using existing drugs declined by $0.7 \%$ over the one-year observation period, whereas that in the app group declined by $1.9 \%$, which is a significant difference (Quinn et al. 2011).

BlueStar achieves its results by allowing users to input their blood glucose levels, medication status, and physical condition. The app analyzes these data to intervene at the appropriate time, allows consultation with specialists, and enables information sharing with a medical team. If its functions in disaster situations can be handled, that is, restrictions on food availability, unmeasured blood glucose levels (or predicted values from wearables), and in case medication is difficult to take, then specialists can provide assistance even during disasters. Disaster prevention, mitigation, and response must rely on the daily use of digital healthcare, particularly among patients with chronic diseases, and on strengthening self-control, which will not change between normal times and disaster.

Mental health care: The importance of mental health was recognized to a greater degree after the Great East Japan Earthquake (Orui et al. 2015). The number of mental health patients does not increase significantly during the hyperacute and acute phases of a disaster but rather tends to increase during the subacute and recovery phases for up to two years later when the surrounding support starts to fade. A disaster psychiatric assistance team (DPAT) and others may provide psychiatric care immediately after a disaster (DPAT Secretariat 2015; Takahashi et al. 2020), which is only acute psychiatric support.

Digital health (Jandoo 2020) has a role in mental health care. Digital approaches for the quantitative assessment of depression and dementia have been developed, and they may become widely used in diagnosis and treatment (Bucci et al. 2019). Martinengo et al. (2019) conducted a systematic evaluation of depression and suicide prevention apps available on the Google Play Store and Apple App Store and found 2,690 apps, with 20 depression management apps, 3 depression management and suicide prevention apps, and 46 suicide prevention apps. These 69 apps were considered to include all of the known evidence regarding suicide prevention. We consider these tools to support the doctor-patient relationship and not a substitute for doctors and other professionals.

However, assuming that a DPAT will be dispatched in the first week after the disaster (or weeks or months if necessary), the use of these digital health apps can ensure a long-term perspective and continued contact with patients. Furthermore, if these apps improve and are adapted to consider a disaster, they may become an even more effective means of response. Such apps may be used by patients as a tool to improve the functioning of their daily practices in psychiatry. Psychiatrists must properly evaluate digital health apps and manage their safety (Fujii et al. 2019). Future disaster prevention, mitigation, and response should incorporate Evidence Based Medicine (EBM) into clinical practice, and the use of digital health apps should be considered.

\section{New value and consensus building}

Infodemics and personal data protection in COVID19: Because of the global outbreak of COVID-19, WHO has sounded the alarm on the negative effects of infodemics (pandemic of information), including the spread of new rumors and misinformation (WHO 2020). An infodemic study reported that more than 800 people died from drinking antiseptics containing methanol and other alcohol components worldwide because of misinformation (Islam et al. 2020). An approach to deal with infodemics during disasters based on a scientific understanding is necessary.

The pandemic response to COVID-19 further stressed the importance of keeping social (physical) distance. As outbreaks spread, digital tracing methods, such as cluster tracking, have been developed and are being used to reduce infections. A simulated study (Kucharski et al. 2020) suggests that the rate of reduction tends to be higher in isolation because of tracking applications. They also infer that high percentages of infected people must be isolated and that high percentages of contacts must be successfully traced to reduce the effective reproduction number to less than one.

Although the importance of contact tracing applications has been shown, in Japan, from the perspective of personal information protection and public sentiment, using them as a personal tool is more practical than a tool managed by the government, which is the case with COCOA, the contact confirmation application released by the MHLW.

However, if individuals can be tracked, imagining how such an approach can be used not only in countermeasures against infectious diseases but also to validate their safety and identify their whereabouts in times of disaster. The handling of personal information and the use of these tools must be considered a matter of urgency to allow the public to give their consent.

\section{The challenges of responding to disasters by $D X$}

The challenge of responding to disasters by DX is that it is affected by the power and telecommunications environment. For example, the benefits of DX are predicated on the stable use of smartphones, which are the operating terminals. It is important that power and telecommunications be supplied even in the event of a disaster, that recovery time be quick even if damage occurs, and that the scope of the impact be small. To solve this problem, Japan has developed the "Energy Supply Enhancement Act" (METI 2020) and is working on small-scale distributed power systems and smart grids (Agency for Natural Resources 2019, 2020). During Typhoon No. 19 in 2019, smart meters were also used to assess the damage. They also provided accurate information to power outages and helped with info- 
demics. Although damage to utility poles hindered the recovery, it is thought that electricity will become more stable if the wires are buried underground (Tokyo Electric Power Grid Co. 2019). In addition, the widespread use of home power generation, storage, and electric vehicles is expected to strengthen the power supply in the immediate aftermath of the disaster (Takagi et al. 2011).

In telecommunications, in addition to the normal power supply for base stations, efforts are being made to prepare for disasters with in-house power generation and storage of power. Large-zone base stations that can cover a wide area, vehicle-type mobile base stations, and satellite systems are being used to ensure early recovery methods (NTT DOCOMO 2017). Local 5G initiatives on a regional, enterprise, and municipal basis have also begun (Toyoshige 2020). Small-scale distributed systems are also expected to prevent congestion and keep telecommunications failures localized.

It is true that a response method that assumes power and telecommunications at the time of disaster involves risks. However, if it is possible to analyze a large amount of information from the IoT (Internet of Things) and other sources during a disaster and take optimal actions by adding our own information, then the benefits sufficiently outweigh the risks.

\section{Conclusion}

In the wake of the Great East Japan Earthquake, methods for disaster prevention, mitigation, and response have been developed and improved. At the same time, innovative services are being created through DX, such as the accelerated deepening of AI technology. Approaches that were once impossible are now possible. These innovative technologies are expected to be practically applicable and to spread to various fields, and the field of disaster response will be no exception.

The digitalization of disaster response requires not literacy (the ability to collect, analyze, and use information) but competence (beneficial behavioral characteristics acquired through experience). That is, understanding behavior through data and behaving rationally are crucial. Human productivity should be increased to improve time efficiency. Then, we will be able to do things that we previously could not because of the lack of time and resources, which is the greatest benefit of DX.

Disaster prevention, mitigation, and response involves the use of our medical information and of digital services in normal times. This approach will protect our lives, and a society where such social services exist will be a more resilient one that can withstand disasters.

\section{Acknowledgments}

Part of this research was conducted as part of a joint research project with Mitsubishi HC Capital Corporation entitled "Research on the Ideal Medical BCP Infrastructure for Individuals and the Optimal Services and Infrastructure for Individuals Using Medical Information," and as part of the Health Labor Sciences Research Grant entitled "Development of a PHR Unification Platform Using the FHIR Next Generation Medical Information Exchange Standard".

\section{Conflict of Interest}

This study was funded by Mitsubishi HC Capital Corporation.

\section{References}

Agency for Natural Resources (2019) Efforts to Strengthen Electric Power Resilience in the Wake of Disasters. https://www.meti.go.jp/shingikai/enecho/denryoku_gas/datsu_ tansoka/pdf/004_03_00.pdf [Accessed: August 10, 2021].

Agency for Natural Resources (2020) Resilience of Electricity from the Perspective of Legal System.

https://www.enecho.meti.go.jp/about/special/johoteikyo/denjihokaisei 04.html [Accessed: August 10, 2021].

Alfano, V. \& Ercolano, S. (2020) The efficacy of lockdown against COVID-19: a cross-country panel analysis. Appl. Health Econ. Health Policy, 18, 509-517.

Astellas Pharma and Welldoc (2019) Astellas and Welldoc Enter into Strategic Alliance for Digital Therapeutics. https://www.astellas.com/jp/system/files/news/201911/20191121_EG_1.pdf [Accessed: July 1, 2021].

Bucci, S., Schwannauer, M. \& Berry, N. (2019) The digital revolution and its impact on mental health care. Psychol. Psychother., 92, 277-297.

Cabinet Office (2013) Business Continuity Guidelines -Strategies and Responses for Surviving Critical Incidents-. http://www.bousai.go.jp/kyoiku/kigyou/pdf/guideline03 en.pdf [Accessed: June 30, 2021].

Cabinet Office (2017) Myna Portal. https://myna.go.jp/ [Accessed: June 30, 2021].

Cabinet Office (2020) White Paper Disaster Management in Japan. http://www.bousai.go.jp/en/documentation/white_paper/pdf/ R2_hakusho_english.pdf [Accessed: June 30, 2021].

CAS (2011) Towards Reconstruction "Hope beyond the Disaster". http://www.cas.go.jp/jp/fukkou/pdf/fukkouhenoteigen.pdf [Accessed: June 30, 2021].

Concato, J. (2020) FDA's real world evidence program. J. Pharm. Pharm. Sci., 23, 6S-9S.

DMAT[MHLW] (2005) What is DMAT? http://www.dmat.jp/dmat/dmat.html [Accessed: June 30, 2021].

DPAT Secretariat (2015) What is DPAT? https://www.dpat.jp/ [Accessed: July 1, 2021].

Dugas, M., Wang, W., Crowley, K., Iyer, A.K., Peeples, M., Shomali, M. \& Gao, G.G. (2020) Engagement and outcomes associated with contextual annotation features of a digital health solution. J. Diabetes Sci. Technol., doi: 10.1177/ 1932296820976409. [Epub ahead of print].

Egawa, S. (2021) Progress of disaster medicine during ten years after the 2011 Great East Japan Earthquake. Tohoku J. Exp. Med., 253, 159-170.

Fujii, S., Nonaka, S. \& Yahagi, N. (2019) Future advantages of EHR and PHR in psychiatric patients. Japanese Journal of Clinical Psychiatry, 48, 1029-1035. 
Fujimori, K. (2019) The Great East Japan Earthquake and Tohoku University Hospital -Maintaining and Restoring Medical Functions.

https://kouseikyoku.mhlw.go.jp/shikoku/kenko_ fukushi/000116381.pdf [Accessed: July 1, 2021].

Fujishiro, H., Matushita, M. \& Ogawara, M. (2018) Effective use of social media in large-scale disasters: the applicability of information triage. Socio-Informatics, 6, 49-63

Fujiwara, I., Kanno, J., Hakoda, A., Nishii, A. \& Igarashi, Y. (2013) Effects of the Great East Japan Earthquake and tsunami on type I diabetic patients: results of a questionnaire survey. $J$. Japan Diabetes Soc., 56, 213-218.

Government of Japan (2002) Health Promotion Law. https://www.mhlw.go.jp/web/t_doc?dataId=78aa3837\&dataTy $\mathrm{pe}=0 \&$ page $\mathrm{No}=1$

[Accessed: June 30, 2021].

Government of Japan (2017) Act on Anonymized Medical Data That Are Meant to Contribute to Research and Development in the Medical Field.

http://www.japaneselawtranslation.go.jp/law/detail/?id=3441 $\& \mathrm{vm}=04 \& \mathrm{re}=01 \&$ new $=1$

[Accessed: June 30, 2021].

Hirokawa, S., Nakura, H. \& Norose, T. (2014) Role of pharmacists in disaster medicine: proposal based on relief efforts during the 2011 earthquake in east Japan. Yakugaku Zasshi, 134, 1-2.

Ido, K., Nakamura, N. \& Nakayama, M. (2019) Miyagi Medical and Welfare Information Network: a backup system for patient clinical information after the Great East Japan Earthquake and tsunami. Tohoku J. Exp. Med., 248, 19-25.

Inoue, M. (2019) Bereaved Families and Hospitals Settle Lawsuits Over Medical Treatment Following Great East Japan Earthquake. The Asahi Shimbun Company.

Ishigaki, A., Higashi, H., Sakamoto, T. \& Shibahara, S. (2013) The Great East-Japan Earthquake and devastating tsunami: an update and lessons from the past Great Earthquakes in Japan since 1923. Tohoku J. Exp. Med., 229, 287-299.

Islam, M.S., Sarkar, T., Khan, S.H., Mostofa Kamal, A.H., Hasan, S.M.M., Kabir, A., Yeasmin, D., Islam, M.A., Amin Chowdhury, K.I., Anwar, K.S., Chughtai, A.A. \& Seale, H. (2020) COVID-19-related infodemic and its impact on public health: a global social media analysis. Am. J. Trop. Med. Hyg., 103, 1621-1629.

Iwaka, K. (2016) Advance recovery efforts in Tokushima prefecture. Disaster Recovery and Revitalization Review, 7, 33-37.

Jandoo, T. (2020) WHO guidance for digital health: what it means for researchers. Digit. Health, 6, 2055207619898984.

JPA (2012a) Activity Report on the Great East Japan Earthquake. https://www.nichiyaku.or.jp/assets/uploads/activities/katsudo hokoku.pdf [Accessed: July 1, 2021].

JPA (2012b) Examples of the use of the Medication Handbook during the Great East Japan Earthquake.

https://www.nichiyaku.or.jp/assets/uploads/activities/shinsai_ techo.pdf

[Accessed: July 1, 2021].

JPA (2016a) E-Yaku Links.

https://www.nichiyaku.or.jp/e_kusulink/

[Accessed: July 1, 2021].

JPA (2016b) What is the e-medication handbook?

https://www.nichiyaku.or.jp/e-okusuri/e-okusuri-02.html [Accessed: July 1, 2021].

JPA (2021) List of e-pharmacy notebooks that are compatible with E-Yaku Links.

https://www.nichiyaku.or.jp/e_kusulink/list.html

[Accessed: July 1, 2021].

Kamimura, M., Hakoda, A., Kanno, J., Nishii, A., Igarashi, Y. \& Fujiwara, I. (2014) Glycemic control in type 1 diabetic patients following the Great East Japan Earthquake and tsunami. J. Japan Diabetes Soc., 57, 16-21.

Khan, S.I., Qadir, Z., Munawar, H.S., Nayak, S.R., Budati, A.K., Verma, K.D. \& Prakash, D. (2021) UAVs path planning architecture for effective medical emergency response in future networks. Physical Communication, 47, 101337.

Kimura, M. (2014) Hospital information system backup for 46 national university hospitals in Japan. -The Gemini Project-. $J$. J. Disast. Medi., 19, 515.

Koido, Y., Kondo, H., Ichihara, M., Kohayagawa, Y. \& Henmi, H. (2011) Research on the DMAT response to the 2011 East Japan Earthquake. J. Natl. Inst. Public Health, 60, 495-501.

Kondo, H., Koido, Y., Kawashima, Y., Kohayagawa, Y., Misaki, M., Takahashi, A., Kondo, Y., Chishima, K. \& Toyokuni, Y. (2019) Consideration of medical and public health coordination - experience from the 2016 Kumamoto, Japan Earthquake. Prehosp. Disaster Med., 34, 149-154.

Kondo, H., Koido, Y., Morino, K., Homma, M., Otomo, Y., Yamamoto, Y. \& Henmi, H. (2012) Establishing disaster medical assistance teams in Japan. Prehosp. Disaster Med., 24, 556-564.

Kucharski, A.J., Klepac, P., Conlan, A.J.K., Kissler, S.M., Tang, M.L., Fry, H., Gog, J.R. \& Edmunds, W.J.; CMMID COVID-19 working group (2020) Effectiveness of isolation, testing, contact tracing, and physical distancing on reducing transmission of SARS-CoV-2 in different settings: a mathematical modelling study. Lancet Infect. Dis., 20, 1151-1160.

Martinengo, L., Van Galen, L., Lum, E., Kowalski, M., Subramaniam, M. \& Car, J. (2019) Suicide prevention and depression apps' suicide risk assessment and management: a systematic assessment of adherence to clinical guidelines. BMC Med., $17,231$.

METI (2018a) Digital Transformation (DX) Report. https://www.meti.go.jp/shingikai/mono_info_service/digital_ transformation/pdf/20180907_03.pdf

[Accessed: June 30, 2021].

METI (2018b) Guidelines for Promoting Digital Transformation Guidelines (DX Promotion Guidelines) .

https://www.meti.go.jp/press/2018/12/20181212004/2018121 2004-1.pdf [Accessed: June 30, 2021].

METI (2020) Cabinet Decision: "Cabinet Order Establishing the Effective Date of Part of the Act for Partial Revision of the Electricity Business Act, etc. for the Purpose of Establishing a Robust and Sustainable Electricity Supply System" was approved by the Cabinet.

https://www.meti.go.jp/press/2020/09/20200925001/2020092 5001.html

[Accessed: August, 10, 2021].

MHLW (2001) Grand Design for Informatization in the Health and Medical Field.

https://www.mhlw.go.jp/shingi/0112/d1/s1226-1.pdf

[Accessed: June 30, 2021].

MHLW (2011a) Damage to Base Hospitals for Disaster Medical Services in the Great East Japan Earthquake.

https://www.mhlw.go.jp/stf/shingi/2r9852000001uo3fatt/2r9852000001uo7y.pdf [Accessed: June 30, 2021]

MHLW (2011b) Damages and Response to Great East Japan Earthquake.

https://www.mhlw.go.jp/file/06-Seisakujouhou-10800000-Iseikyoku/0000103405.pdf

[Accessed: July, 1, 2021]

MHLW (2014) Promotion of ICT in the fields of health, medical care, and nursing care.

https://www.mhlw.go.jp/file/06-Seisakujouhou-12600000Seisakutoukatsukan/0000042495.pdf

[Accessed: June 30, 2021].

MHLW (2016) Regional comprehensive care system. https://www.mhlw.go.jp/stf/seisakunitsuite/bunya/hukushi 
kaigo/kaigo_koureisha/chiiki-houkatsu/

[Accessed: June 30, 2021].

MHLW (2017a) About Data Health Reform Promotion Headquarters.

https://www.mhlw.go.jp/file/05-Shingikai-12601000-SeisakutoukatsukanSanjikanshitsu_Shakaihoshoutantou/0000148418.pdf [Accessed: June 30, 2021].

MHLW (2017b) Data Health Reform Promotion Headquarters. https://www.mhlw.go.jp/stf/seisakunitsuite/bunya/0000148743. html

[Accessed: June 30, 2021].

MHLW (2017c) Guide to Creating a Data Health Plan, Revised Edition.

https://www.mhlw.go.jp/file/06-Seisakujouhou12400000-Hokenkyoku/0000201969.pdf

[Accessed: June 30, 2021].

MHLW (2018) Guidelines for the Appropriate Implementation of Online Medical Care.

https://www.mhlw.go.jp/content/000534254.pdf

[Accessed: June 30, 2021].

MHLW (2019a) Ministry of Health, Labour and Welfare Disaster Prevention Work Plan.

https://www.mhlw.go.jp/content/10800000/000648237.pdf [Accessed: July 1, 2021].

MHLW (2019b) Outline of the Act on the Partial Revision of the Health Promotion Act.

https://www.mhlw.go.jp/english/policy/health-medical/health/ dl/201904kenko.pdf

[Accessed: June 30, 2021].

MHLW (2019c) Results of a survey on the development of business continuity plans (BCPs) for hospitals. https://www.mhlw.go.jp/content/10800000/000533729.pdf [Accessed: June 30, 2021].

MHLW (2020) Centralized Reform Plan for Data Health that Responds to New Routine. https://www.mhlw.go.jp/content/12601000/000653403.pdf [Accessed: June 30, 2021].

MHLW[COCOA] (2021) Investigation into the circumstances surrounding the occurrence of a problem with the contact confirmation application "COCOA" and consideration of measures to prevent recurrence.

https://www.mhlw.go.jp/content/000769774.pdf

[Accessed: June 30, 2021].

MIC (2012) The Great East Japan Earthquake and Business Continuity.

https://www.soumu.go.jp/johotsusintokei/whitepaper/ja/h24/ pdf $/$ n3020000.pdf

[Accessed: June 30, 2021].

MIC (2021) Results of a survey on the status of business continuity planning in local governments.

https://www.soumu.go.jp/main_content/000743471.pdf

[Accessed: June 30, 2021].

MLIT (2021a) Guidelines for the Delivery of Goods and Services Using Drones.

https://www.mlit.go.jp/common/001396667.pdf

[Accessed: July 1, 2021].

MLIT (2021b) Study Group on Drone Logistics Business Models in Depopulated Areas, etc.

https://www.mlit.go.jp/seisakutokatsu/freight/seisakutokatsu_ freight_tk1_000191.html

[Accessed: July 1, 2021].

Mora, P., Biggs, W.C. \& Parkin, C.G. (2019) Optimizing mHealth technologies in real-world clinical practices. Clin. Diabetes, 37, 269-275.

Moshref-Javadi, M. \& Winkenbach, M. (2021) Applications and research avenues for drone-based models in logistics: a classification and review. Expert Syst. Appl., 177.

Nakamoto, I., Jiang, M., Zhang, J., Zhuang, W., Guo, Y., Jin, M.H., Huang, Y. \& Tang, K. (2020) Evaluation of the design and implementation of a peer-to-peer COVID-19 Contact Tracing Mobile App (COCOA) in Japan. JMIR Mhealth Uhealth, 8, e22098.

Nakamura, K. (2011) Advance reconstruction and disaster prevention community planning. Urban Housing Studies, 2011, 43-49.

Nakayama, M., Inoue, R., Miyata, S. \& Shimizu, H. (2021) Health information exchange between specialists and general practitioners benefits rural patients. Appl. Clin. Inform., 12, 564-572.

Nomura, K., Inoue, S. \& Yano, E. (2009) The shortage of pediatrician workforce in rural areas of Japan. Tohoku J. Exp. Med., 217, 299-305.

NTT DOCOMO (2017) NTT DOCOMO's Disaster Response Measures.

https://www.nttdocomo.co.jp/binary/pdf/corporate/csr/ disaster/saigai torikumi.pdf [Accessed: August, 10, 2021].

Orii, T. (2018) Current status and issues of electronic information provision for risk minimization: coordination between electronic medicine notebook and patient drug information. Yakugaku Zasshi, 138, 325-329.

Orui, M., Sato, Y., Tazaki, K., Kawamura, I., Harada, S. \& Hayashi, M. (2015) Delayed increase in male suicide rates in tsunami disaster-stricken areas following the Great East Japan Earthquake: a three-year follow-up study in Miyagi Prefecture. Tohoku J. Exp. Med., 235, 215-222.

Porumb, M., Stranges, S., Pescape, A. \& Pecchia, L. (2020) Precision medicine and artificial intelligence: a pilot study on deep learning for hypoglycemic events detection based on ECG. Sci. Rep., 10, 170.

Quinn, C.C., Shardell, M.D., Terrin, M.L., Barr, E.A., Ballew, S.H. \& Gruber-Baldini, A.L. (2011) Cluster-randomized trial of a mobile phone personalized behavioral intervention for blood glucose control. Diabetes Care, 34, 1934-1942.

Reconstruction Agency (2020) Status of Reconstruction from Great East Japan Earthquake and Reconstruction Efforts. https://www.reconstruction.go.jp/english/topics/Progress to date/202009_Pamphlet_fukkonojokyototorikumi_English.pdf [Accessed: June 30, 2021].

Reconstruction Agency (2021) Number of evacuees nationwide. https://www.reconstruction.go.jp/topics/main-cat2/sub-cat21/20210528 houdou1.pdf [Accessed: June 30, 2021].

Roche Diabetes Care (2021) Accu-Chek Connect Online. https://www.accu-chek.ca/en/data-management/connectonline [Accessed: June 30, 2021].

Sasaki, H., Maruya, H., Abe, Y., Fujita, M., Furukawa, H., Fuda, M., Kamei, T., Yaegashi, N., Tominaga, T. \& Egawa, S. (2020) Scoping review of hospital business continuity plans to validate the improvement after the 2011 Great East Japan Earthquake and tsunami. Tohoku J. Exp. Med., 251, 147-159.

Sasako, S. (2020) Data health reform promoted by the Ministry of Health, Labour and Welfare.

https://www.kantei.go.jp/jp/singi/titeki2/tyousakai/kousou/ 2020/dai3/siryou4.pdf [Accessed: June, 30, 2021].

Schwab, K. (2015) The Fourth Industrial Revolution: what it means, how to respond.

https://www.weforum.org/agenda/2016/01/the-fourthindustrial-revolution-what-it-means-and-how-to-respond/ [Accessed: June 30, 2021].

Steinbrook, R. (2020) Contact tracing, testing, and control of COVID-19-learning from Taiwan. JAMA Intern. Med., 180, $1163-1164$

Stolterman, E. \& Fors, A.C. (2004) Information technology and the good life. In: Information Systems Research: Relevant Theory and Informed Practice, Springer, Boston, MA, pp. 
687-692.

Sung, J.J., Stewart, C.L. \& Freedman, B. (2020) Artificial intelligence in health care: preparing for the fifth Industrial Revolution. Med. J. Aust., 213, 253-255. e251.

Takagi, K., Takeda, D. \& Iino, Y. (2011) Smart Grid Technologies for robust power supply infrastructure against disaster. https:/www.global.toshiba/content/dam/toshiba/migration/ corp/techReviewAssets/tech/review/2011/08/66_08pdf/a03. pdf [Accessed: August 10, 2021].

Takahashi, S., Takagi, Y., Fukuo, Y., Arai, T., Watari, M. \& Tachikawa, H. (2020) Acute mental health needs duration during major disasters: a phenomenological experience of Disaster Psychiatric Assistance Teams (DPATs) in Japan. Int. J. Environ. Res. Public Health, 17, 1530.

Takahashi, K. (2014) Policies for the Elderly in the Ministry of Health, Labor and Welfare. http://www.moj.go.jp/content/000123298.pdf [Accessed: June 30, 2021].

Takata, H., Nagata, H., Nogawa, H. \& Tanaka, H. (2011) The current shortage and future surplus of doctors: a projection of the future growth of the Japanese medical workforce. Hum. Resour. Health, 9, 14.

Tanaka, H. (2012) Healthcare IT system in the midst of and after Great East Japan Earthquake Disaster grand design for reconstruction of Tohoku-region healthcare IT system. Journal of Information Processing and Management, 54, 825-835.

Tanno, Y. (2014) Role of pharmacists during serious natural disasters: report from Ishinomaki, the disaster-struck city. Yakugaku Zasshi, 134, 19-23.

Tokyo Electric Power Grid Co. (2019) Response to Restoration of Power Outage (Report).

https://www.tepco.co.jp/press/release/2019/pdf4/191031j0204. pdf

[Accessed: August 10, 2021].

Tokyo Metropolitan Government (2001) Grand Design for Disaster Reconstruction of Tokyo Metropolitan Government. https://www.toshiseibi.metro.tokyo.lg.jp/bosai/gd/honbun.htm [Accessed: July 1, 2021].

Tokyo Metropolitan Government (2012) Medical care in times of disaster.

https://www.fukushihoken.metro.tokyo.lg.jp/iryo/kyuukyuu/ saigai/index.html

[Accessed: July 1, 2021].

Tokyo Metropolitan Government (2015) TOKYO BOUSAI.

https://www.bousai.metro.tokyo.1g.jp/content/ kurashi_2/01tokyobousai.pdf

[Accessed: July 1, 2021].

Tokyo Metropolitan Government (2019) Tokyo Metropolitan
Government Disaster Prevention Website.

https://www.bousai.metro.tokyo.lg.jp/bousai/1000027/1000344. $\mathrm{html}$

[Accessed: July 1, 2021].

Toyoshige, H. (2020) Utilization of $5 \mathrm{G}$ in the disaster prevention field.

https://www.soumu.go.jp/main_content/000672983.pdf [Accessed: August 10, 2021].

Ujiie, K. (2013) Comprehensive metropolitan and district-level support system for large-scale disasters: prefectural government pharmaceutical administration system support for largescale earthquake disaster preparation. J. Natl. Inst. Public Health, 62, 405-413.

UN (2015) THE 17 GOALS. https://sdgs.un.org/goals [Accessed: June 30, 2021].

UN (2016a) Make cities and human settlements inclusive, safe, resilient and sustainable.

https://sdgs.un.org/goals/goal11 [Accessed: June 30, 2021].

UN (2016b) Sendai Framework for Disaster Risk Reduction 20152030.

https://www.preventionweb.net/files/43291_sendaiframework fordrren.pdf [Accessed: June 30, 2021].

Watanabe, D. (2017) Current status and issues of the electronic version of the medication handbook.

https://www.mhlw.go.jp/file/05-Shingikai-11121000Iyakushokuhinkyoku-Soumuka/0000183061.pdf [Accessed: July 1, 2021].

Welldoc (2021) Digital Health Platform For Chronic Care | Welldoc. https://www.welldoc.com/ [Accessed: July 1, 2021].

WHO (2016) Patient Engagement: Technical Series on Safer Primary Care.

http://apps.who.int/iris/bitstream/handle/10665/ 252269/9789241511629-eng.pdf

[Accessed: June 30, 2021].

WHO (2020) 1st WHO Infodemiology Conference. https://www.who.int/news-room/events/detail/2020/06/30/ default-calendar/1st-who-infodemiology-conference [Accessed: July 1, 2021].

Xiao, D., Song, C., Nakamura, N. \& Nakayama, M. (2021) Development of an application concerning fast healthcare interoperability resources based on standardized structured medical information exchange version 2 data. Comput. Methods Programs Biomed., 208, 106232. 